\title{
Probing Hairpin Structures of Small DNAs by Nondenaturing Polyacrylamide Gel Electrophoresis
}

\author{
Ulrich Baumann, ${ }^{*, 1}$ Ronald Frank, $\dagger$ and Helmut Blöcker $\dagger$ \\ *Max-Planck-Institut für Biophysikalische Chemie, D-3400 Göttingen, Federal Republic of Germany, \\ and $† G B F, D N A-S y n t h e s e g r u p p e$, Braunschweig, Federal Republic of Germany
}

The influence of temperature on the electrophoretic mobility of small DNAs, capable of forming hairpin structures, is investigated under nondenaturing conditions. Three series of hairpin-forming DNAs containing different numbers of thymidine, deoxyadenosine, and deoxyguanosine residues in their loop, and an identical sequence in the helical region, are analyzed. All show enhanced electrophoretic mobility if they adopt the hairpin conformation. The same quantitative relationship between hairpin formation and increase in electrophoretic mobility is observed for all of the three series. The constancy of this increase suggests a dependence of electrophoretic acceleration on the length of the helical region. A possible application of nondenaturing electrophoresis is monitoring the hairpin/coil transition. Another possible application is the detection of dimers formed by partially self-complementary sequences. This dimer formation is detected for completely complementary DNAs, whereas sequences which might form imperfect double helices, especially those with three bulged-out nucleotides, prefer hairpin formation. The possible applications are experimentally approached and discussed. (c) 1989 Academic Press, Inc.

The secondary and tertiary structures of nucleic acids influence their electrophoretic mobility in polyacrylamide and agarose gels. In the high molecular weight range the most significant effect is the enhanced mobility of double-stranded, compared to single-stranded, DNA revealed by application of a gradient of a denaturing agent (1). Supercoiled plasmids move faster than the relaxed form; the number of supercoils is directly related to the electrophoretic behavior of a plasmid $(2,3)$. Bended double-stranded DNA shows reduced mobility (4), as well as DNA containing cruciforms (5) in compar-

\footnotetext{
${ }^{1}$ To whom correspondence should be addressed.
}

ison to linear structures. Single-stranded DNAs, generated from blunt end duplexes, migrate at different rates due to variations in secondary structure of both strands $(6,7)$. Furthermore, the two-dimensional separation of tRNAs is based on their different tertiary structures (8).

Hairpins formed by concatemers in the range of 8-80 nucleotides exhibit enhanced mobility, although denatured by urea (9). In this study rather small oligodeoxynucleotides, capable of forming single hairpin structures, are investigated by nondenaturing polyacrylamide gel electrophoresis. The temperature dependence of electrophoretic mobility reveals enhanced mobility of the hairpin form. As the temperature range of transition from hairpin to random coil of the DNAs investigated is known from independent studies $(10,11)$, the electrophoretic mobility can be unambiguously correlated to their secondary structure. Thus, the method promises to be useful for monitoring hairpin/random coil transition and might supplement NMR and temperature dependence of ultraviolet absorption. Its advantages include the application of more physiological concentrations and reduced consumption of materials.

\section{MATERIALS AND METHODS}

\section{Materials}

The hairpin-forming DNAs 5 -d(CTATCCTAA 6 TAGGATAG) as well as $h p(d G)_{3-5}$ and $h p(d A)_{3,4,6}{ }^{2}$ were synthesized by phosphotriester chemistry on cellulose disks acting as segmental support (12). The hairpins $\mathrm{hp}(\mathrm{dT})_{3-6}$ and $\mathrm{hp}(\mathrm{dA})_{5}$ were synthesized according to Ref. (13). Oligo(dA $)_{12-18}$, oligo(dT) ${ }_{12-18}$ (both in a $5^{\prime}$ phosphorylated and dephosphorylated form), oligo $(\mathrm{dC})_{12-18}$, oligo $(\mathrm{dA})_{19-30}$, and oligo(dAG) $)_{5}$, all bearing a $5^{\prime}$ phosphate group, were from Pharmacia (Freiburg, FRG).

\footnotetext{
${ }^{2}$ Abbreviations used: $h p(d G)_{3-5}, h p(d A)_{3-6}, h p(d T)_{3-6}=5^{\prime}-d(A T C$ CTAN $_{3-6}$ TAGGAT), N being either $d G, d A$, or $d T ; ~ h p=$ hairpin.
} 


\section{Methods}

Nondenaturing polyacrylamide gel electrophoresis was performed in a thermostatable apparatus of submarine type (SE 600, Hoefer Scientific, San Francisco, CA). Gels of $14 \times 16 \times 0.05 \mathrm{~cm}$ and of $20 \%$ acrylamide/bisacrylamide (ratio 20:1) were exclusively used. The electrophoresis buffer was $50 \mathrm{~mm}$ Tris, $50 \mathrm{~mm}$ boric acid, 1 mM EDTA. For proof of dimer formation $10 \mathrm{~mm}$ magnesium acetate was added to the buffer $\left(10 \mathrm{mM} \mathbf{M g}^{2+}\right.$ causes problems of electrophoresis at $60^{\circ} \mathrm{C}$, only one electrophoresis was performed at this temperature). The loading buffer (14) was supplemented for nondenaturing electrophoresis with $30 \%$ sucrose $(w / v)$ instead of $10 \mathrm{M}$ urea. Electrophoresis under denaturing conditions was performed according to published procedures (14). The temperature was controlled within a range of $\pm 0.5^{\circ} \mathrm{C}$. Prior to electrophoresis at low temperatures, the hairpin-forming DNAs were incubated for $5 \mathrm{~min}$ at $65^{\circ} \mathrm{C}$ in a buffer consisting of $10 \mathrm{mM}$ Tris $/ \mathrm{HCl}, \mathrm{pH} 7.2 ; 10 \mathrm{mM}$ $\mathrm{NaCl} ; 5 \mathrm{mM} \mathrm{MgCl} \mathrm{m}_{2}$ and cooled slowly to the desired temperature. This was performed in order to obtain an identical structural state of each DNA hairpin before start of an experiment. The gels were stained by Stains-all $\left(0.01 \%\right.$ in $\mathrm{H}_{2} \mathrm{O} /$ formamide $\left.1: 1(\mathrm{v} / \mathrm{v})\right)$. The applied voltage was held constant at $600 \mathrm{~V}(=48 \mathrm{~V} / \mathrm{cm})$ because the field strength also renders the electrophoretic mobility. All experiments regarding the hairpin conformation of a DNA were performed at $10^{\circ} \mathrm{C}$ in order to obtain smooth bands, this temperature is below helix/coil transition (10) and gives the same result as electrophoresis at $0^{\circ} \mathrm{C}$. Deviations from these standard conditions are assigned in the legends.

\section{RESULTS}

\section{Quantitative Evaluation of the Enhanced Mobility of the Hairpin Form}

Three series of hairpin-forming oligodeoxynucleotides were analyzed for their electrophoretic mobility in polyacrylamide gels applying nondenaturing conditions. All of the DNA hairpins, as shown in Fig. 1, have an idential sequence in the double-helical region and differ only in the loop region which contains a different number of thymidine, deoxyadenosine, or deoxyguanosine residues. The hairpin structure adopted below $10^{\circ} \mathrm{C}$ was proven for $\mathrm{dT}$-containing series by NMR and temperature dependence of ultraviolet absorption $(10,11)$. Similar values of $T_{m}$ are assumed for the other two series. This is likely because the bigger part of the oligonucleotides, 66 to $75 \%$, is helical. As this part is identical for the three series, the different free energies of the loops cause an expected maximum difference in $\mathrm{T}_{m}$ of approximately $10^{\circ} \mathrm{C}$. An example of dramatic change in $\mathrm{T}_{m}$ induced by a different loop structure was reported (15), but in that case the helical region of the hairpin comprised only $36 \%$ of the molecule.

$$
\begin{aligned}
& \text { 5'-d (AT CCTA A } \\
& \text { (TAGGÁT A }
\end{aligned}
$$

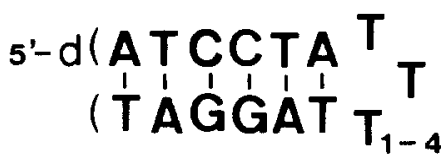

$$
\begin{aligned}
& \begin{aligned}
& \text { 5'-d } \text { ( A T CCTA } \mathbf{G}_{\mathbf{G}} \\
& \text { ( T' AGGAT } \mathbf{G}_{1-3}
\end{aligned}
\end{aligned}
$$

FIG. 1. Sequence of the investigated series of hairpin-forming oligodeoxyribonucleotides.

The electrophoretic mobility of the three series of hairpin-forming DNAs was evaluated by comparison with the mobilities of single-stranded standards oligo$(\mathrm{dA})_{12-18}$, oligo $(\mathrm{dT})_{12-18}$, oligo $(\mathrm{dC})_{12-18}$, and oligo $(\mathrm{dG})_{n}$. All three series of hairpin-forming DNAs show the same enhanced mobility up to $10^{\circ} \mathrm{C}$, below this temperature they adopt the hairpin conformation, compared to mobility at $60^{\circ} \mathrm{C}$ where they exist as random coil, see Figs. 2 and 3 . The enhanced mobility of the hairpin form becomes qualitatively evident when the mobilities of single-stranded $p(d A G)_{5}$ and $h p(d T)_{3}$, revealed at different temperatures, are compared, see lanes $d$ and e in Fig. 2. Two other effects which influence the mobility of small oligonucleotides have to be considered. The mobility of small DNAs is sequence, as well as temperature dependent (16). Both disturbing effects can be evaluated by using standards, as the effects are small or inversely related to mobility changes caused by different conformations. In Fig. 2 the electrophoretic behavior of series $\mathrm{hp}(\mathrm{dT})_{3-6}$ at two temperatures, 10 and $60^{\circ} \mathrm{C}$, is compared with that revealed under denaturing conditions. Experimental mobility values are compared with theoretical ones, which are calculated assuming a single-stranded structure. At constant temperature the mobility of a single-stranded oligodeoxynucleotide is only dependent on the overall nucleotide content and not on the sequence; therefore, the formula can be applied (16)

$$
\begin{aligned}
& x\left(\mathrm{~T}_{t} \mathrm{~A}_{a} \mathrm{C}_{c} \mathrm{G}_{g}\right) \\
& \quad=\frac{t}{n} * x\left(\mathrm{~T}_{n}\right)+\frac{a}{n} * x\left(\mathrm{~A}_{n}\right)+\frac{c}{n} * x\left(\mathrm{C}_{n}\right)+\frac{g}{n} * x\left(\mathrm{G}_{n}\right) \\
& t+a+c+g=n ; \text { number of monomers } \\
& x\left(\mathrm{~T}_{n}\right), x\left(\mathrm{~A}_{n}\right) \\
& =\text { mobility of homooligonucleotides of length } n .
\end{aligned}
$$




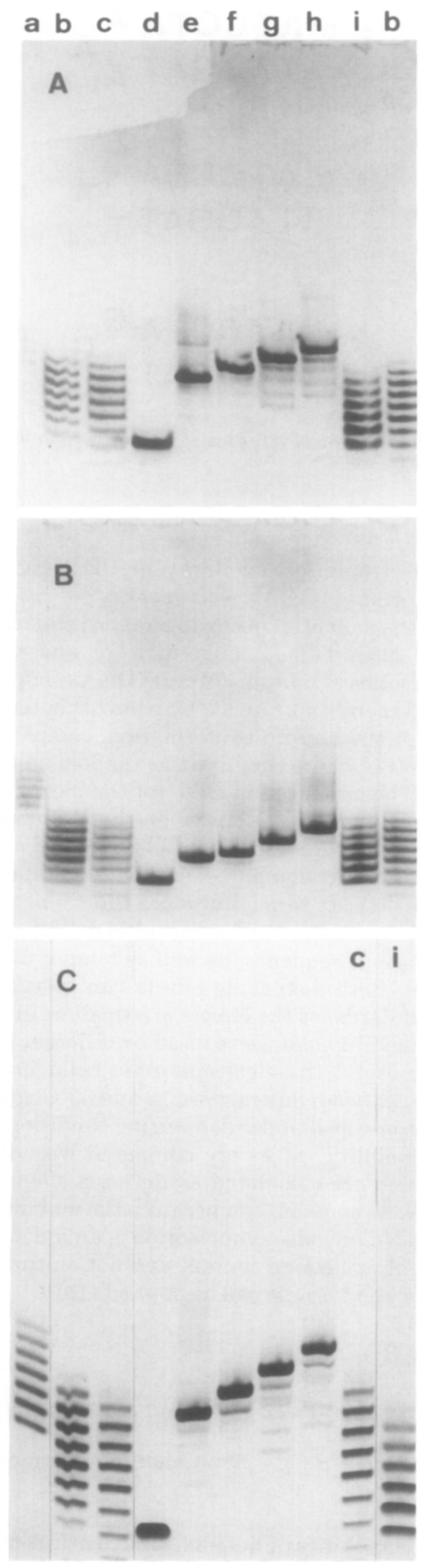

TABLE 1

\begin{tabular}{|c|c|c|c|c|}
\hline \multirow{2}{*}{$\begin{array}{l}\text { Hairpin- } \\
\text { forming } \\
\text { DNA }\end{array}$} & \multicolumn{2}{|c|}{$\begin{array}{l}\text { Mobility } x \\
\text { (cm) }\end{array}$} & \multirow{2}{*}{$\begin{array}{c}\text { Acceleration (\%) } \\
x_{\text {exp. }} / x_{\text {calc. }} * 100-100\end{array}$} & \multirow{2}{*}{$\begin{array}{c}\text { Average } \\
\text { acceleration } \\
(\%)\end{array}$} \\
\hline & Calc. & Exp. & & \\
\hline Hairpin $(\mathrm{dT})_{3}$ & 7.00 & 8.10 & 15.7 & 17.4 \\
\hline Hairpin $(\mathrm{dT})_{4}$ & 6.77 & 7.95 & 17.4 & \\
\hline Hairpin $(\mathrm{dT})_{5}$ & 6.51 & 7.70 & 18.8 & \\
\hline Hairpin $(\mathrm{dT})_{6}$ & 6.37 & 7.45 & 16.9 & \\
\hline Hairpin $(\mathrm{dA})_{3}$ & 8.76 & 10.10 & 15.0 & 15.3 \\
\hline Hairpin $(\mathrm{dA})_{4}$ & 8.47 & 9.70 & 14.5 & \\
\hline Hairpin $(\mathrm{dA})_{5}$ & 8.25 & 9.65 & 17.0 & \\
\hline Hairpin $(\mathrm{dA})_{6}$ & 8.06 & 9.25 & 14.8 & \\
\hline Hairpin $(\mathrm{dG})_{3}$ & 7.38 & 8.40 & 13.8 & 15.2 \\
\hline Hairpin $(\mathrm{dG})_{4}$ & 7.01 & 8.05 & 14.8 & \\
\hline Hairpin $(\mathrm{dG})_{5}$ & 6.67 & 7.80 & 16.9 & \\
\hline
\end{tabular}

Note. The increased electrophoretic mobility of the hairpin form is expressed in relation to the mobility of random coil which is set to $100 \%$. The calculation of the theoretical mobility (calc.) assuming a single-stranded structure was performed as described in the text, these values are compared with the experimental values (exp.) revealed from electrophoresis at $10^{\circ} \mathrm{C}$.

The basis of the calculation are the experimental values of homooligonucleotides $x\left(\mathrm{~T}_{n}\right), x\left(\mathrm{~A}_{n}\right)$, etc. These values are derived directly from gels run at different temperatures. As oligo $(\mathrm{dG})_{n}$ forms clusters consisting of several molecules (17), the mobility value of oligo(dG) ${ }_{n}$ was indirectly determined from that of $\mathrm{p}(\mathrm{dGA})_{5}$. For this purpose, first the value of $(\mathrm{dA})_{5}$ was determined from that of oligo $(\mathrm{dA})_{12-18}$ by averaging the ratio $r_{A}=x\left(\mathrm{~A}_{n-1}\right) /$ $x\left(\mathrm{~A}_{n}\right)$ for each gel. This ratio is rather constant. By calculating $r_{G}=\sqrt[5]{x\left(\mathrm{~A}_{5}\right) / x\left(\mathrm{AG}_{5}\right)}$ the ratio $x\left(\mathrm{G}_{n-1}\right) / x\left(\mathrm{G}_{n}\right)$ was determined. By means of this ratio, first the mohility of $(\mathrm{dG})_{1}$ and then that of $(\mathrm{dG})_{n}$ were determined. This determination is less accurate than the directly determined values for other homooligonucleotides. But one must consider that all of the hairpin series, expect $\mathrm{hp}(\mathrm{dG})_{3-5}$, contain only two deoxyguanosine residues. An experimental error of $10 \%$ for the mobility of oligo $(\mathrm{dG})_{n}$ would result only in an error of $1.5 \%$ for mobility of a DNA hairpin. As all hairpins bear no $5^{\prime}$ phosphate group whereas oligo $(\mathrm{dC})_{n}$ and $\mathrm{p}(\mathrm{dAG})_{5}$ contain it, the effect of one additional phosphate group was evalu-

FIG. 2. Electrophoretic behavior of $h p(d T)_{3-6}$ below and above the hairpin/random coil transition. In the respective lane $0.05 A_{260}$ unit of the hairpin-forming DNA is applied and the electrophoresis is performed together with single-stranded marker oligonucleotides. Three different conditions, (A) nondenaturing at $60^{\circ} \mathrm{C}$, (B) nondenaturing at $10^{\circ} \mathrm{C}$, and $(\mathrm{C})$ denaturing at ca. $50^{\circ} \mathrm{C}$. Lane a $(\mathrm{dT})_{12-18}$, lane b (dA) ${ }_{12-18}$, lane $c p(d A)_{12-18}$, lane $d p(d A G)_{5}$, lane e hp(dT) $)_{3}$, lane $f$ $\mathrm{hp}(\mathrm{dT})_{4}$, lane $\mathrm{g} \mathrm{hp}(\mathrm{dT})_{5}$, lane $\mathrm{h} \mathrm{hp}(\mathrm{dT})_{6}$, and lane $\mathrm{i} \mathrm{p}(\mathrm{dC})_{12-18}$. The two outer lanes in (C) are changed, compared to $A$ and $B$, as indicated. 


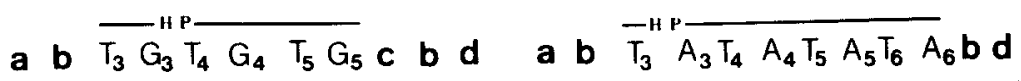

A

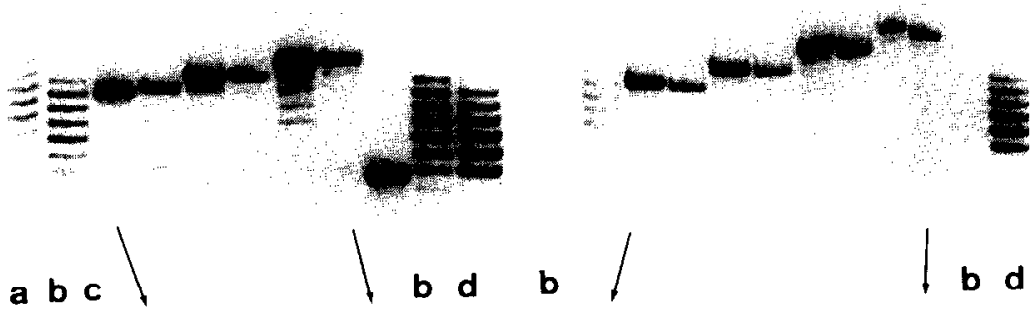

B

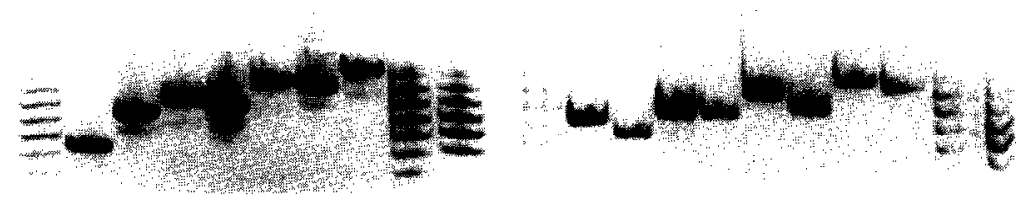

FIG. 3. Comparison of $h p(d A)_{3-6}$ and $h p(d G)_{3-5}$ with the electrophoretic mobility of $h p(d T)_{3-6} .(A)$ Electrophoresis at $60^{\circ} \mathrm{C}$ and $(\mathrm{B})$ at $10^{\circ} \mathrm{C}$, both under nondenaturing conditions. Lane a $(\mathrm{dT})_{12-18}$, lane $\mathrm{b}(\mathrm{dA})_{12-18}$, lane $\mathrm{c} p(\mathrm{dGA})_{5}$, lane $\mathrm{d} \mathrm{p}(\mathrm{dC})_{12-18}$, and different hairpin-forming $\mathrm{DNAs}$ as indicated; $d$ for deoxy is omitted to simplify the figure.

ated by comparing the $5^{\prime}$ phosphorylated and dephosphorylated form of $(\mathrm{dA})_{12-18}$ and $(\mathrm{dT})_{12-18}$. The effect was small (see Fig. 2), and the $5^{\prime}$ phosphorylated molecules show the same mobility as a dephosphorylated oligonucleotide shortened by half a nucleotide, this was considered in the determination of $x\left(\mathrm{C}_{n}\right)$ and $x\left(\mathrm{G}_{n}\right)$.

Theoretical values of mobility calculated from a gel run at $60^{\circ} \mathrm{C}$ are in good agreement with experimental values indicating that all DNAs are present as random coil at this temperature. The mobilities of each of the hairpin forms are given in Table 1 . The values are expressed as excess percentage assuming $100 \%$ for the random coil. These values lie between 13.8 and $17.4 \%$. They are significantly greater than the deviation of experimental and theoretical values at $60^{\circ} \mathrm{C}$ which are in the range $\pm 2 \%$. The apparent size of a DNA hairpin is three to four nucleotides smaller than the true size. The average values of acceleration are $17.2 \%$ for dT-containing series, $15.2 \%$ for $\mathrm{dG}$ series, and $15.3 \%$ for $\mathrm{dA}$ series. The last two series are shown in Fig. 3 in comparison to thymidine containing DNA hairpins. The constancy of relative enhancement indicates, at least for the $\mathrm{dG}$ - and dA-containing series, that the effect caused by hairpin formation is not dependent on the sequence of the loop but is only dependent on the length of the helical region. If this is true a means to determine the size of the doublehelical region of a hairpin structure would be established.

\section{Application of the Enhanced Mobility of DNA Hairpins}

First, one can determine if a small DNA might adopt a hairpin conformation. If an indication for hairpin formation is given, one can determine the thermal dependence of the transition and the stability of a hairpin structure. In Fig. 4 the electrophoretic pattern at $40^{\circ} \mathrm{C}$ for $h p(d T)_{3-6}$ in comparison with $h p(d A)_{3-6}$ is shown. This temperature is within phase transition of all hairpin-forming DNAs. The oligonucleotide $\mathrm{hp}(\mathrm{dT})_{3}$ exhibits an acceleration of $7.4 \%, \mathrm{hp}(\mathrm{dT})_{4}$ of $7.8 \%$, the fivemembered loop $3.8 \%$, and the six membered loop $0 \%$. The values for full hairpin form listed in Table 1 are around $17 \%$. A hairpin electrophoresed at its $\mathrm{T}_{m}$ would hence give a mobility increase of about $8 \%$. It is concluded that bigger loops $h p(d T)_{5}$ and $h p(d T)_{6}$ have a lower $\mathrm{T}_{m}$ as $40^{\circ} \mathrm{C}$, whereas $\mathrm{T}_{m}$ of small loops is very near 

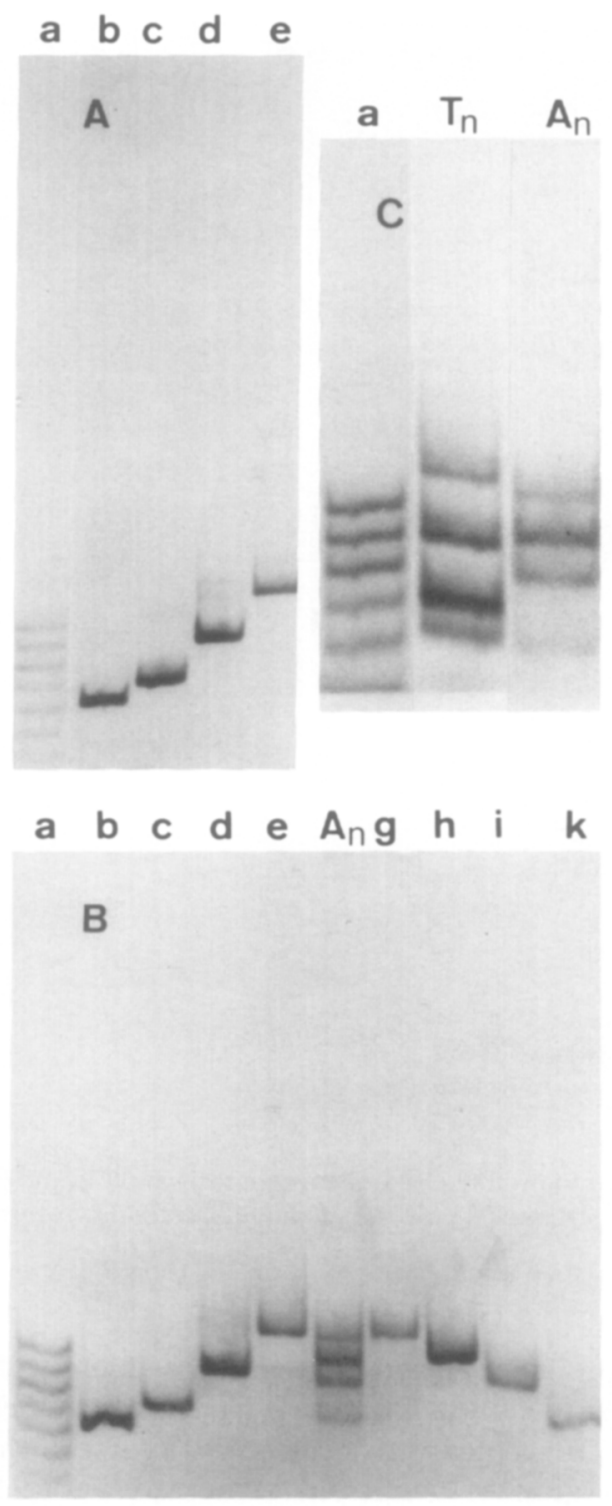

FIG. 4. Electrophoretic pattern of the DNA hairpins within helix/ coil transition at $T=40^{\circ} \mathrm{C}$. (A) The series $\mathrm{hp}(\mathrm{dT})_{3-6}$ and (B) the series

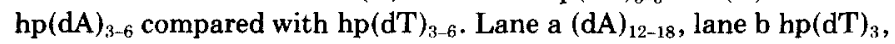
lane $c h p(d T)_{4}$, lane $d h p(d T)_{5}$, lane e $h p(d T)_{6}$, lane $g h p(d A)_{6}$, lane $h$ $h p(d A)_{5}$, lane $i h p(d A)_{4}$, and lane $k h p(d A)_{3}$. The label $A_{n}$ indicates the mixture of the four hairpins $h p(d A)_{3-6}$. (C) An enlarged section from a separation of $h p(d T)_{3-6}$ (indicated by $T_{n}$ ) is shown in comparison with $\mathrm{hp}(\mathrm{dA})_{3-6}$ and single-stranded $(\mathrm{dA})_{12-18}$. The lanes for (dA) ${ }_{12-18}$ and $T_{n}$ are from the same gel; lane $A_{n}$ is from a different gel. Note the different band distances revealed by the two hairpin series and the enhanced distances between hairpins from the same series differing in one monomer.

to this temperature. This observation supports results from NMR (10) that the most stable hairpin DNA from the series containing four to seven thymidines in the loop is that with a four-membered loop and that stability decreases with increase in loop size to seven nucleotides. As the behavior of $h p(d T)_{3}$ is close to the full hairpin form, it is concluded that this hairpin structure is at least as stable as $\mathrm{hp}(\mathrm{dT})_{4}$. The reported $\mathrm{T}_{m}$ values are $44^{\circ} \mathrm{C}$ for $h p(d T)_{3}(11)$ and $h p(d T)_{4}, 40^{\circ} \mathrm{C}$ for $h p(d T)_{5}$, and $36^{\circ} \mathrm{C}$ for $\mathrm{hp}\left(\mathrm{d}^{\mathrm{T}}\right)_{6}(10)$. The values are determined at 15 $\mathrm{mM} \mathrm{Na}{ }^{+}$and are thus slightly higher than our estimation, because no salt is present during electrophoresis. The series containing deoxyadenosine residues in the loop shows that the hairpin structure of $h p(d A)_{3}$ is considerably more stable than $\mathrm{hp}(\mathrm{dA})_{4}$, because both DNAs are separated by a greater distance as expected for one additional nucleotide (see Fig. $4 \mathrm{C}$ ). Thus, the method can also be used to improve separation of hairpin-forming DNAs with slightly different stability if electrophoresis is performed near the average $T_{m}$. The separation of single-stranded and hairpin-forming DNAs may be improved by variation of the electrophoresis temperature.

This simple method clearly shows that oligonucleotides with a three-membered loop do not exist as a dimer with three bulged-out nucleotides in the concentration range applied. To prove this fact, $h p(d T)_{3}$ and $h p(d A)_{3}$, which are fully complementary, were annealed at $0^{\circ} \mathrm{C}$ and run in parallel with $\mathrm{hp}(\mathrm{dA})_{3}$ in the presence of 10

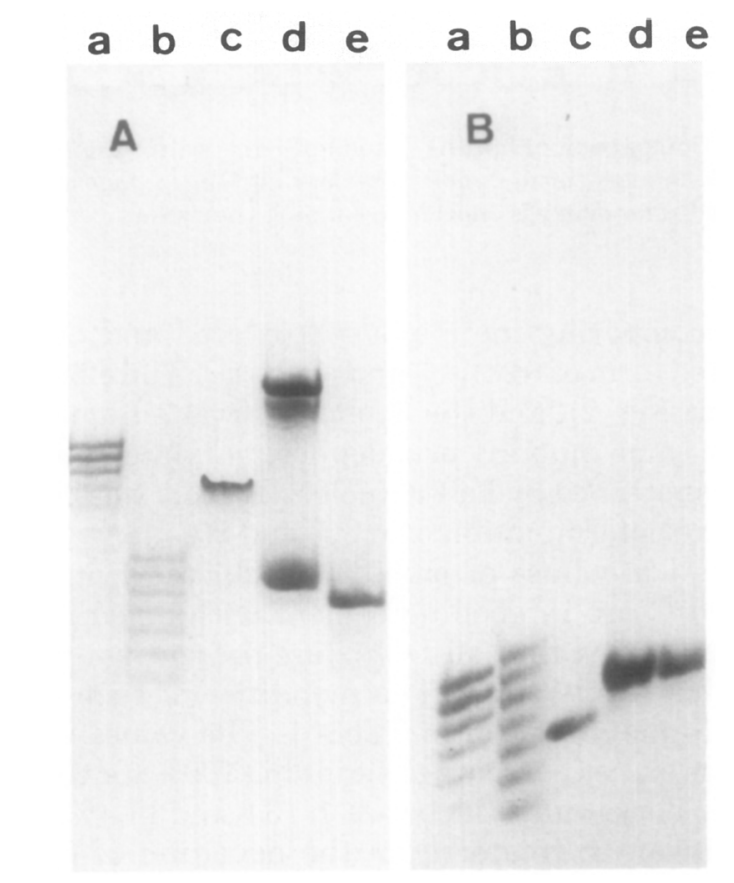

FIG. 5. Dimer formation of completely complementary $h p(d T)_{3}$ and $\mathrm{hp}(\mathrm{dA})_{3}$ at $0^{\circ} \mathrm{C}$. The hairpin-forming DNAs hp $(\mathrm{dT})_{3}$ and $\mathrm{hp}(\mathrm{dA})_{3}, 0.1$ $A_{260}$ unit of each, were heated for $5 \mathrm{~min}$ to $65^{\circ} \mathrm{C}$, then annealed in a buffer consisting of $10 \mathrm{mM}$ Tris/ $\mathrm{HCl}, \mathrm{pH} 7.2,10 \mathrm{mM} \mathrm{NaCl}$, and $10 \mathrm{mM}$ $\mathrm{MgCl}_{2}$ for $5 \mathrm{~min}$ at $0^{\circ} \mathrm{C}$, total volume $4 \mu \mathrm{l}$ (lane d), and electrophoresed at $0^{\circ} \mathrm{C}(\mathrm{A})$ and $60^{\circ} \mathrm{C}(\mathrm{B})$ in a gel containing $10 \mathrm{mM}$ magnesium acetate. The hairpin-forming DNA hp $(\mathrm{dA})_{3}$ was used as a control demonstrating no dimer formation under these conditions. Lane a $(\mathrm{dT})_{12-18}$, lane b $(\mathrm{dA})_{12-18}$, lane c p $(\mathrm{dAG})_{5}$, lane $\mathrm{d}$ mixture of $\mathrm{hp}(\mathrm{dA})_{3}$ and $\mathrm{hp}(\mathrm{dT})_{3}$, and lane $e \mathrm{hp}(\mathrm{dA})_{3}$. 
$\mathrm{mM} \mathrm{Mg}^{2+}$ (see Fig. 5). Under these conditions a dimer of $\mathrm{hp}(\mathrm{dA})_{3}$ and $\mathrm{hp}(\mathrm{dT})_{3}$ is formed and is stable during electrophoresis, whereas $\mathrm{hp}(\mathrm{dA})_{3}$ shows the molecular weight of the monomer. This indicates that in the concentration range considered, $0.12-0.3 \mathrm{mM}$, hairpin-forming DNAs with a three-membered loop do not exist as an imperfect duplex even in the presence of $10 \mathrm{mM} \mathrm{Mg}{ }^{2+}$. The partial dimer formation detected by NMR (11) might be possible in the NMR concentration range being 10- to 30 -fold higher.

All the hairpin series tested have an idential helix length and their relative increase of mobility is quantitatively similar. Therefore, it was presumed that the degree of acceleration is only dependent on the length of the helical region. To test this assumption, the electrophoretic mobility of a hairpin-forming structure with six adenosine residues in the loop, the same loop as in $\mathrm{hp}(\mathrm{dA})_{6}$, and a prolonged helix consisting of 8 instead of $6 \mathrm{bp}$ was analyzed. The sequence was $5^{\prime}-\mathrm{d}(\mathrm{CTA}$ TCCTAA 6 TAGGATAG). The electrophoretic pattern, shown in Fig. 6, exhibits as expected an acceleration effect of the hairpin form. Interestingly, it shows two bands at this temperature and only one main band under denaturing conditions. Quantitative evaluation gives an increase in mobility of $12.9 \%$ for the intense, upper band and $16 \%$ for the less intense, faster moving band.

\section{DISCUSSION}

With regard to the unusual electrophoretic mobility of DNA structures revealed by previous studies two groups are distinguishable. Single-stranded DNA is assumed to behave normally. Structures causing electrophoretic acceleration are closed circular (18) and supercoiled DNA, present in plasmids (2), as well as double strands in the high molecular weight range (1). Slower moving structures are bended DNA, those DNAs and RNAs bearing single- and double-stranded parts in the same molecule as well as stable cruciforms $(4,5)$. It is concluded that all structural elements leading to closer packing, but not rendering the overall rod-like shape of molecules, increase the electrophoretic mobility. Elements leading to complex branching, in contrast, result in decrease of DNA mobility. Therefore, it is not surprising that the formation of a single hairpin of the investigated oligonucleotides cause electrophoretic acceleration. The change of shape is similar to that of plasmids during supercoiling. The degree of acceleration is mainly dependent on the size of the helical region, because all hairpins reveal similar values independent of their loop size and nucleotide content. This dependence on the helix length, however, seems not to be very sensitive. The extension of the helix from 6 to $8 \mathrm{bp}$ does not significantly increase the accelerating effect. The effect of helix extension is only examined for one hairpin, further investigations are necessary. The emergence of two bands for this oligonucleo-
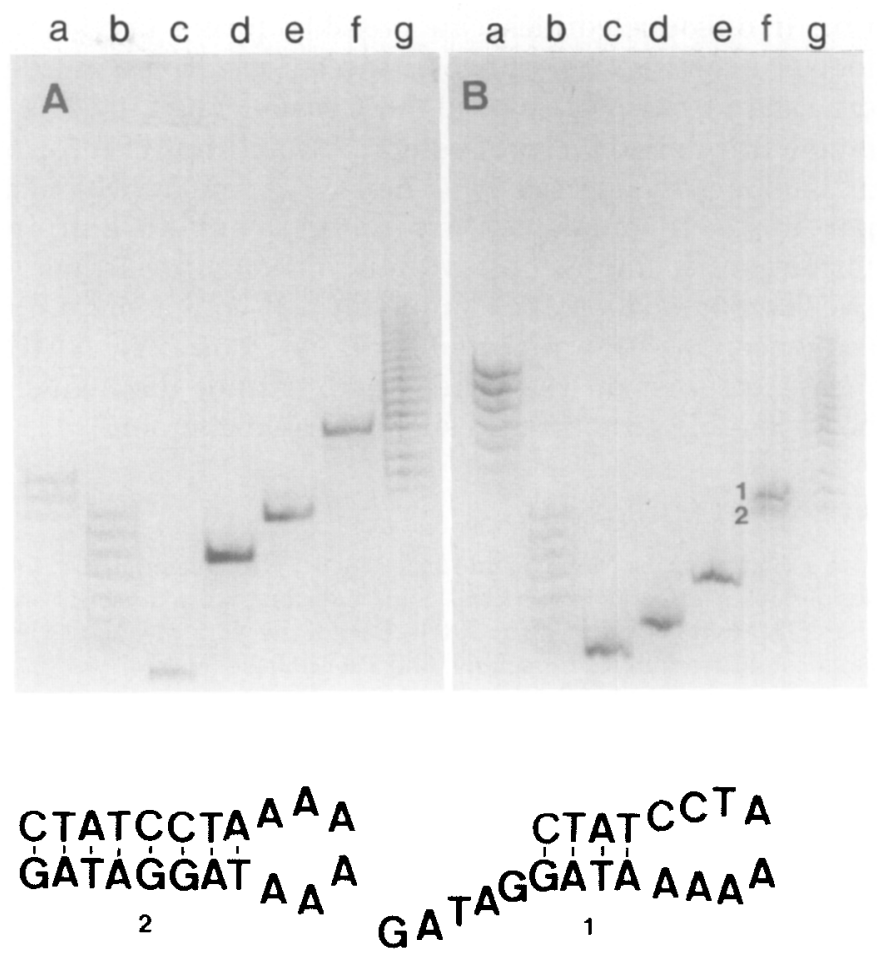

FIG. 6. Increase of the mobility of a hairpin-forming DNA with prolonged helix. The mobility of the hairpin $5^{\prime}$-d(TCATCCTAA A TAGG- $_{6}$ ATGA) (lane $\mathrm{f}$ ) was determined at $60^{\circ} \mathrm{C}(\mathrm{A})$ and at $5^{\circ} \mathrm{C}(\mathrm{B})$ under standard conditions. The emergence of two bands at $5^{\circ} \mathrm{C}$ might be due to the formation of two different hairpins as shown below the gel patterns; indication $d$ for deoxy and of the $5^{\prime}$ end are omitted to clarify the picture. Lane a $(\mathrm{dT})_{12-18}$, lane b $(\mathrm{dA})_{12-1 k}$, lane $c \mathrm{p}(\mathrm{dAG})_{5}$, lane $\mathrm{d}$ $\mathrm{hp}(\mathrm{dA})_{3}$, lane $\mathrm{hp}(\mathrm{dA})_{5}$, and lane $\mathrm{g} \mathrm{p}(\mathrm{dA})_{19-3)}$.

tide, on the other hand, indicates that this bigger DNA might form two different hairpin structures with different lengths of the helical region which are possibly formed and also shown in Fig. 6.

The $T_{m}$ values for $d G$ and $d A$ series were not determined independently and might significantly differ from those of dT series. We assumed a similar stability for the three series. Two facts support the assumption: First, the agreement between theoretical and experimental mobilities at high temperature and second, the constancy of the accelerating effect at low temperature. Thus, the method presented may supplement established techniques as NMR and temperature dependence of ultraviolet absorption. This method requires much less material and also requires very simple equipment. It is certainly limited to small oligonucleotides, because additional structural elements are easily introduced with increase of size; these would prevent unambiguous interpretation. In addition, the amount of information regarding distinct base pairs and stacking of loop nucleotides which have been evaluated by NMR (19) or accessibility to a single-strand-specific nuclease $(20,21)$ is more limited when this method is applied. The ques- 
tion if oligonucleotides can possibly form very small loops consisting only of two or three nucleotides, on the other hand, can be answered more easily. The fully complementary oligonucleotides $\mathrm{hp}(\mathrm{dA})_{3}$ and $\mathrm{hp}(\mathrm{dT})_{3}$ form a dimer, easily detected by its molecular weight, whereas partially self-complementary $\mathrm{hp}(\mathrm{dA})_{3}$ prefers hairpin formation. A similar observation, although regarding a two-membered loop of a completely self-complementary sequence, has been reported by Xodo et al. (22). NMR measurements, on the other hand, cannot distinguish both possible structures in such a simple manner.

\section{ACKNOWLEDGMENTS}

We thank Drs. D. Möbius and L. De Maeyer (Göttingen, FRG), for support of the work. For critical comments on the manuscript we thank D. Mellerick (Göttingen, FRG). Part of the work was funded by Bundesministerium für Forschung und Technologie.

\section{REFERENCES}

1. Fischer, S. G., and Lerman, L. S. (1980) Proc. Natl Acad. Sci. USA $77,4420-4424$.

2. Keller, W. (1975) Proc. Natl Acad. Sci. USA 72, 4876-4880.

3. Gellert, M., Mizuuchi, K., O'Dea, M. H., and Nash, H. A. (1976) Proc. Natl Acad. Sci. USA 73, 3872-3876.

4. Diekmann, S., and Wang, J. C. (1985) J. Mol. Biol. 186, 1-11.

5. Gough, G. W., and Lilley, D. M. J. (1985) Nature (London) 313 , 154-156.

6. Hayward, G. S. (1972) Virology 49, 342-344.

7. Maxam, A. M., and Gilbert, W. (1977) Proc. Natl Acad. Sci. USA 74, 560-564.
8. Fradin, A., Gruhl, H., and Feldmann, H. (1975) FEBS Lett. 50, 185-189.

9. Frank, R., Müller, D., and Wolff, C. (1981) Nucleic Acids Res. 9, 4967-4979.

10. Haasnot, C. A. G., de Bruin, S. H., Berendsen, R. G., Janssen, H. G. J. M., Binnendijk, T. J. J., Hilbers, C. W., van der Marel, G. A., and van Boom, J. H. (1983) J. Biomol. Struct. Dyn. 1, 115129.

11. Haasnot, C. A. G., de Bruin, S. H., Hilbers, C. W., van der Marel, G. A., and van Boom, J. H. (1985) J. Biosci. 8 (Suppl.), 767-780.

12. Frank, R., Heikens, W., Heisterberg-Moutsis, G., and Blöcker, H. (1983) Nucleic Acids Res. 11, 4365-4377.

13. van Boom, J. H., van der Marel, G. A., Westerink, H., van Boeckel, C. A. A., Mellema, J.-R., Altona, C., Hilbers, C. W., Haasnot, C. A. G., de Bruin, S. H., and Berendsen, R. G. (1982) Cold Spring Harbor Symp. Quant. Biol. 47, 403-409.

14. Donis-Keller, H., Maxam, A. M., and Gilbert, W. (1977) Nucleic Acids Res. 4, 2527-2538.

15. Nadeau, J. G., and Gilham, P. T. (1985) Nucleic Acids Res. 13, 8259-8274.

16. Frank, R., and Köster, H. (1979) Nucleic Acids Res. 6, 2069-2086.

17. Lipsett, M. N. (1964) J. Biol. Chem. 239, 12501255.

18. Johnson, P. H., and Grossman, L. I. (1977) Biochemistry 16, 4217-4225.

19. van de Ven, F. J. M., and Hilbers, C. W. (1988) Eur. J. Biochem. 178, 1-38.

20. Baumann, U., Frank, R., and Blöcker, H. (1986) Eur. J. Biochem. 161, 409-413.

21. Baumann, U., Lehmann, U., Schwellnus, K., van Boom, J. H., and Kuhn, H. (1987) Eur. J. Biochem. 170, 267-272.

22. Xodo, L. E., Manzini, G., Quadrifoglio, F., van der Marel, G. A., and van Boom, J. H. (1988) Biochemistry 27, 6321-6326. 